\title{
Introducing a Model for Implementation of Industrial Policies: A Case Study in Qom Province, Iran
}

\author{
Rahmatollah Gholipour ${ }^{1, *}$, Gholamrea Jandaghi ${ }^{1}$, Mohammad Reza Fallah ${ }^{2}$ \\ ${ }^{1}$ University of Tehran, Iran \\ ${ }^{2}$ Department of Management, Hazrat-e Masoumeh University, Iran \\ rgholipor@ut.ac.ir, jandaghi@ut.ac.ir,mfallah@hmu@ut.ac.ir
}

\begin{abstract}
The Model for Implementation of Industrial Policies in Qom Province presented in this paper has five stages which respectively include: culturalization of implementation, Capacity-building of Implementation, entrepreneurial Implementation, the synergy in the implementation and finally the successful implementation of industrial policies.
\end{abstract}

Keywords Implementation of Policies, Approaches for Implementation of Policies, Culturalization of Implementation, Capacity-building for Implementation, Entrepreneurial Implementation, Synergy in the Implementation, Successful Implementation of Industrial Policies

\section{Introduction}

One of the most important issues that today almost all countries, both developed and developing countries are facing with is the issue of failed implementation of policies. So in this case, many efforts have been done to provide a framework and model for successful implementation of policies by the scientists of policy making and implementation fields that we can name them as follows: "the approach Top-Down", "approach of Bottom-Up" and "a Synthesis approach".

In this approach, various frameworks and theories have emerged as possible within the frameworks such as Sabatier, Edvard, Calista and etc. research methodology in this research is Qualitative. In this research, exploratory interviews and grounded theory were used to collect data and modeling. Also in this study validated interview is used for testing the model ant.

\section{Approaches to Policy Implementation}

The literature shows three methods for studying, a Top-Down approach, Bottom-Up approach and the Synthesis approach.

A) Approaches "top-down"

In the approach "top-down", the elites are at the top of the pay legislation and comments of people is not involved in

* Corresponding author:

rgholipor@ut.ac.ir(Rahmatollah Gholipour)

Published online at http://journal.sapub.org/economics

Copyright $(2012$ Scientific \& Academic Publishing. All Rights Reserved decision-making. This view is in fact the theory of elites and the mass of people, here the policies are dependent to the demands of superiors and hierarchy levels and the senior leaders of the organization make the decisions themselves.

The first attempt at presenting a model based approach "Top-Down ", was conducted in 1975 by Van Meter and Van Horn. Their models consisted of six variables that include: standards and objectives, policy resources, and activities between organizations and executive activities, specifications of administrative, economic, social, political parts and enforcement trends. These variables create relations between implementation and policy (Van Meter and Van Horn, 1975, p476-462).

One of the other frameworks "top-down" was developed in 1980 by Sabatier and Mazmanian. According to their model, the most vital role in implementation of policies is identifying the variables in achieving policies that affect them during the process. These variables are classified into three main categories which include: nature variables, structural variables and background variables.

Another Top-Down model was developed by Edwards in 1980. In this model, four of the reasons that influence over policy implementation are identified (Edwards, 1980, p. 148): 1) communication, 2) resources, 3 ) enforcement trends, 4) bureaucratic structure.

Various models have been presented based on the model "Top-Down ". But all these models which are presented in this field, they have neglected the most fundamental and essential variables (Pressman and Wildavsky,1984; Hargrove, 1980; Ingram, 1987; Wegner, 1987).

B) "Bottom-Up approach"

Johnson and O'Connor 1979 acknowledge that the executors who stay in the front lines won't necessarily wel- 
come the guidelines and instructions of Top-Down approach; because they deal directly with customers needs and clients and they are aware of those orders high levels of the organization to make the real issues and challenges, and more conscious of the problems that occur in the implementation.

So they need a broader role in setting the rules. This does not mean that at all, "street-level bureaucracy" should make the policies themselves and to design the executive prescriptions themselves and do them (Palumbo and Calista, 1987).

In the "Bottom-Up approach" it is the policy rather than by the policy makers which can control, through explicit and implicit negotiation between the organization and its customers can be explained.

So the program should be consistent with hopes and wishes, or at least with the behavior patterns of lower officials (Linder and Peters, 1987).

Regarding Bottom-Up approach there are various models, one of the models that is mostly named as "backward mapping" has been created by elmore in 1978. Models in this policy rather than be controlled by policy makers, they are controlled through negotiation and bargaining (explicit and implicit) between members of the organization and its customers.

So the programs should be consisted with hopes and wishes, or at least with the behavior patterns of lower officials (Linder and Peters, 1987). This approach has also received much criticism because it assumes that policy implementation occurs in a decentralized environment (Linder and Peters, 1987; Sabatier, 1980, Lenny, 1983, Kisser and Ostrom, 1983).

While the Bottom-Up approach may face with fewer problems, but it is an idealist perspective; the problem laid in the society can not be determined by ordinary people. This theory is also being implemented to be one hundred percent. The Bottom-Up approach is the thinking process of political and economic which will follow public policy (Howlett, 1995, p. 156). Bottom-Up approach due to its idealist perspective can face with much problems. Maybe the lack of success by the scientists in combination of these two approaches and access to a comprehensive model has led them toward another model (Howlett and Ramesh, 2003, pp 252-251).

C) Synthesis (hybrid) Approach

This approach has hybrid outlook which concentrates on the complicities process of negotiation and bargaining between actors of policy in all the policy levels and planning process (Barnett and Fudge , 1981, Barnett and Hill, 1984; Goggin 1990; Barnett, 2004).

Hybrid approach, sometimes referred to as third generation of executive studies (Goggin et al, 1990). The Synthesis approach combines a mix of approaches Top-Down and Bottom-Up approach in a way that it has the strengths of both of them and they have used the weakness of each other as opportunities.

Barnett and Fudge (1981) argue that there is a false dichotomy between Top-Down approach and Bottom-Up approach and it can be imagined that both approaches can be used simultaneously. Implemented when seeking to limit the legal from Top-Down and when it seeks to reduce the level of actors of policy it occurs from Bottom-Up (Barnett and Fudge, 1981, p. 25).

The first attempts to combine the both models of the policy took place in the United States and it was conducted in 1985 by Richard Elmore. He combined his previous work that was named "backward mapping" with his new work that was named "forward mapping".

In this combination, he stated that policy makers must pay attention to political institutions, and other resources that are available and the ultimate goal of motivating groups. However, his model does not provide graphics for the policy implementation process.

The second attempt to combine the models of policy implementation was done by Sabatier and Jenkins in 1993 that led to the formulation of a framework called "partisan coalition framework" for the study of policy subsystems.

The third approach attempts to combine elements of Top-Down approach and Bottom-Up approach by Goggin in 1987. In the of intergovernmental implementation model it is stated that implementation is indeed a function of motivations, tools and limitations which have been created for the government from another place. However, government choices of rational actors are not committed, but may result of dealings between internal and external parties that are involved in other government policies. Thus, this approach assumes that implementation of government programs on the federal outcome variables which are developed on the Top-Down approach and Bottom-Up approach.

Calista expresses four institutional contents for implementation of public policies that paying attention to them causes that implementation to be done accurately and effectively in the policy making process (Calista, 1995, p. 117). Four stages of implementation and effective factors for them based on the comment of Kalysta include:

A - First level of "content agency" or "constitution" that emphasizes on legal and institutional aspects and how its behavior is subject to the guidelines, rules and regulations adopted by the institutions.

B - The second level, "the election of candidates" as "collective choice" which actually creates legitimacy for the model, this content has been involved with organizations and administrative space. This level will lead to better policies imposed by the collective agreement to be implemented.

C - Third level of "operational level" and the action of government in which the government tries to ratify rules and internal regulations. This includes the quasi-governmental and nongovernmental institutions, and decisions made at this level consist of the formal and informal decisions.

D- Fourth Level of "Distribution Level" in which the management includes provides services and the government by using it supervisors on the operations and this content coordinates the contents of other results and makes them ready for the implementation stage in their external gathering and it has almost a complete level (Razghi Rostami, 2000, p. 
$54)$.

\section{Research Objectives and Questions}

The main goal of this research is to provide a model for implementation of industrial policies in Qom province. This research will also look for other secondary purposes that include:

1 - Exact considering of the concept of policy making and implementation of industrial policies

2 - Considering of theories, models and frameworks of policy making and implementation

3 - Determining the key variables affecting implementation

4 - Considering the relation between variables

5 - Identifying the structures and instruments in the implementation of industrial policies

6 - Presenting a framework for the implementation of industrial policies

Main question:

The main research question is 'how is the implementation model for industrial policies in Qom province?

Subsidiary questions:

1 - What are the key variables affecting implementation of industrial policies in Qom province?

2 - What are the barriers and bottlenecks for implementation of industrial policies in Qom province?

\section{Research Methodology}

In this study, qualitative approach has been used to gather datum and data analysis. The above mentioned model has been provided based on exploratory interviews using the data collected and analyzed based on interviews with the GROUNDED THEORY (GT) model.

To write "Research theoretical principles" the methods of library was used and information is collected from various primary and secondary sources. Methods for collecting data and variables were done by considering the records, documents, interviews and questionnaires.

As mentioned before, this research presents a conceptive model for implementation of industrial polices and its domain is limited to Qom province and all the managers and employees that work in this industry. According to the importance of subject of research in both sections of interviews meaning exploratory interview and comparative interviews, the model of snowball sampling or chain sampling is used to select the interviewees. In the snowball method, at first few people were selected as sample population and then we asked each of them to introduce some persons to us (Jandaghi and Fallah, 2010, p. 34).

\section{Data Analysis and Presenting a Model}

"The model for implementation of policies in Qom province" which is the result of current study consists of five main phases and steps, which respectively include: "Culturalization of implementation "Capacity-building of Implementation", "entrepreneurial in Implementation", "the synergy on the Implementation" and finally "the successful implementation of industrial policies".

The first phase consists of the two models "common understanding of provincial Industrial policies "and "provincial arrangement for implementation of industrial policies" and in this regard, the "provincial arrangement for implementation of industrial policies" or "pre-preparation for implementation" is divided into two sections of "internal factors" and "external factors".

In the second phase "Capacity-building of Implementation" or Implementation Empowerment will occur as empowerment, including "software capacity," software capacity" and "skills capacity.

The third phase includes "entrepreneurial in Implementation" is the kind of creativity, innovation and risk taking that is the result of Culturalization of implementation of industrial policies and it accelerates the procedure of implementation of policies in the provinces.

The fourth stage is the "synergy in implementation of industrial policies which is the result of atmosphere for implementation of industrial policies and it is based on "entrepreneurial in Implementation" and "Culturalization of implementation".

When "The atmosphere for implementation of industrial policies" causes that some phenomena such as "a provincial commitment to implementation", "management support", "adjustment of administrative bureaucracy","Horizontal public administration ", "The optimal allocation of resources and facilities" and "using appropriate administrative tools" to occur in implementation of industrial policies and eventually the fifth stage of "successful implementation of industrial policies" will happen.

Culturalization of implementation

\section{Successful Implementation of Industrial Policies}

The most important question that might be asked by anyone in this section is: what are the results of four above stages including "Culturalization of implementation", "capacity building of implementation", "Implementation entrepreneurship" and finally "synergy in implementation"?

Since the main purpose of this thesis is presenting a model for implementation of industrial policies in Qom Province and according to the results provided from exploratory interviews in the initial stages and the results of narration interviews at the end of this work, it can be said that using this model is based on the use of steps, stages and processes that are predicted for that and they will be followed successful implementation of industrial policies in Qom province. Of course it will be a result of Culturalization, empowerment, entrepreneurship and synergy in implementation of industrial policies in Qom province. 

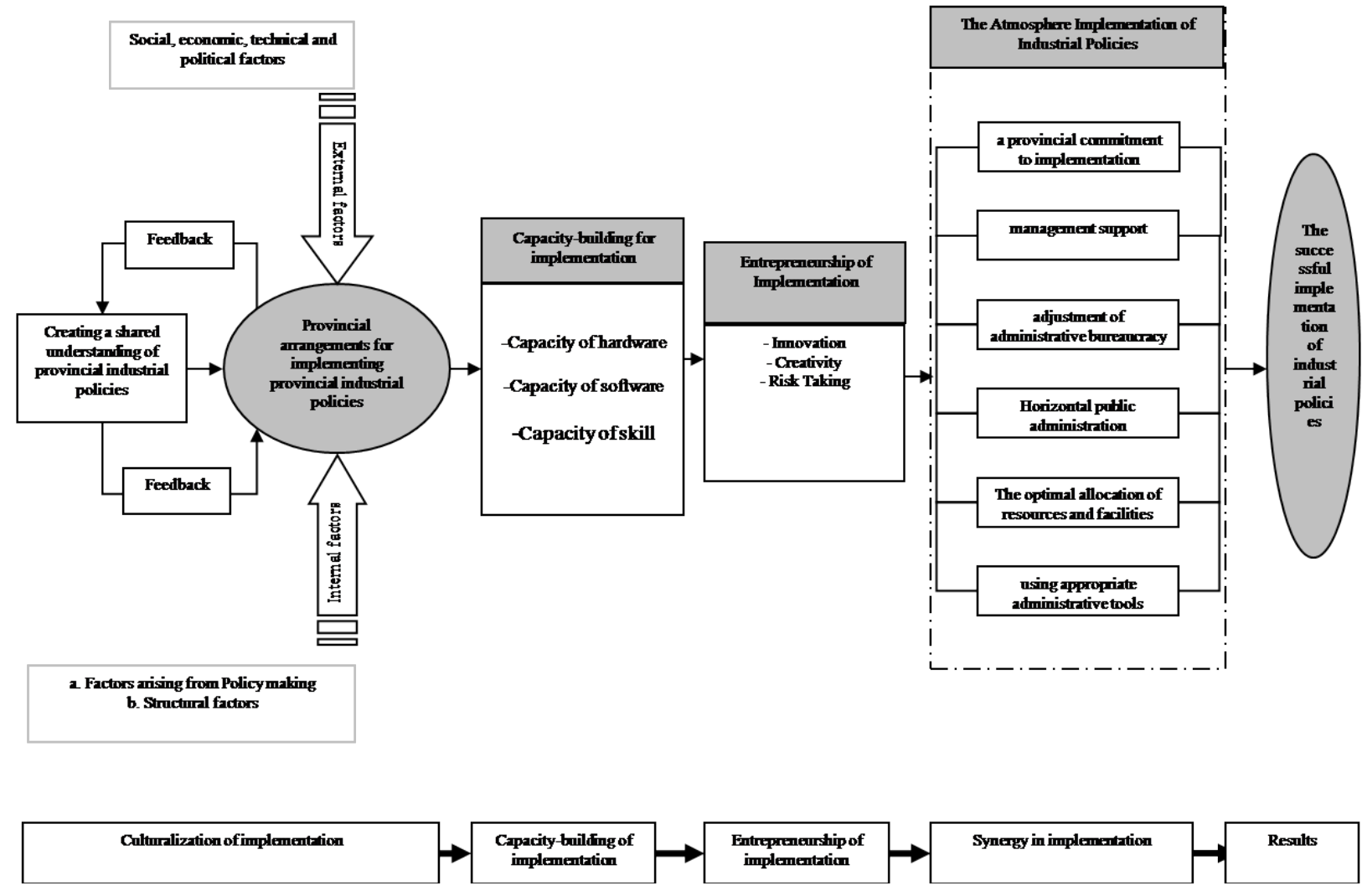

\section{Conclusions}

Based on the results provided from the datum of initial exploratory interviews and the modeling that has been done based on the G.T analysis and the narrations based on interviews that have been done after compiling and designing the model, it can be concluded that in order to have a successful implementation of industrial policies in Qom province, we must pay attention to different factors and actors that directly and indirectly affect the process of implementation and by creating a common provincial understanding regarding the industrial policies and pre-preparation for implementation, it can be anticipated that the procedure of implementation with capacity building and creation of entrepreneurship which will be followed with creativity, invention and risking, it will create an appropriate atmosphere for successful implementation of industrial policies.

\section{REFERENCES}

[1] Barrett, S., Fudge, C., (1981) Examining the Policy-action Relationship. Methuen: London.

[2] Barrett, S., Hill, M., (1984) Policy, Bargaining and Structure in Implementation Theory. Policy and Politics, 12, 3,

[3] Barrett, S. (2004). Implementation Studies: Time for a Revival? Personal Reflections on 20 Years of Implementation Studies. Public Administration 82(2)
[4] Calista, D. 1995. "Policy Implementation.".Encyclopedia of Policy Studies edited by S. Nagel. New York: Marcel Dekker.

[5] Elmore, R., (1978) Organisational Models of Social Program Implementation. Public Policy, 26, 2.

[6] Gholipour 2008, Rahmatullah. Organizational and public policy decisions, Samt Publication, Winter 2008

[7] Goggin, Malcolm and Bowman, Ann and Lester, James and O'Toole, Laurence. (1990). Implementation Theory and Practice, Toward a Third Generation. Illinois: Scott, Foresman/Little, Brown Higher Education.

[8] Hargrove, Barbara. 1980. "Evil Eyes and Religious Choices." Society, 17, 3:

[9] Howlett, M., and M. Ramesch. 1995. Studying Public Policy: Policy Cycles and Policy Subsystems. Toronto: OUP.

[10] Howlett, M., and M. Ramesch. 2003. Studying Public Policy: Policy Cycles and PolicySubsystems [2nd ed.]. Toronto: OUP.

[11] Johnson, RW and RE O' Connor (1979). Intra - agency limitation on policy implementation: you can't always get what you want, but sometimes you get what you need'. In Administration and Society.

[12] Linder, S., Peters, G., (1987) A Design Perspective On Policy Implementation. Policy Studies Review, 6, 3.

[13] Mazmanian, D. A., \& Sabatier, P. A. (1981). Effective Policy Implementation. Lexington, MA: Lexington Books.

[14] Milward, H. B., \& Francisco, R. A. (1983). Subsystem politics and corporatism in the United States. Policy and Politics, 11 
(3),

[15] Ostrom, E., Gardner, R. And Walker, J. (1994) Rules, Games and Common Pool Resources, Ann Arbor,

[16] Palumbo \& D. J. Calista (Eds.)(1987) Implementation and the Policy Process: Opening up the Black Box, (pp. 19-38). New York: Greenwood Press

[17] Pressman, J.L. and A. Wiidavsky. 1984. Implementation. Berkeley: University of California Press.

[18] Razghi Rostami, Ali Reza, Pathology of Implementation of industrial policies, Third International Conference on Management, Thesis for $\mathrm{PhD}$ degree in Governmental Manage- ment field (policy focus), 2005.

[19] Sabatier, P. A. \& Jenkins-Smith, H. C., eds. (1993). Policy Change and Learning: An Advocacy Coalition Approach. Westview Press, Boulder, pp. 13-39.

[20] Sabatier, P.A., Mazmanian, D., (1979) The Implementation of Public Policy: A Framework of Analysis. Policy Studies Journal, 8.

[21] Sabatier, Paul.(1991) "Towards Better Theories of the Policy Process." Political Science and Politics June .

[22] Van Meter, D., Van Horn, C., (1975) The Policy Implementation Process. Administration and Society, 6, 4, . 